\title{
Defective lysosomal proteolysis and axonal transport are early pathogenic events that worsen with age leading to increased APP metabolism and synaptic Abeta in transgenic APP/PS1 hippocampus
}

\author{
Manuel Torres ${ }^{1,2,3}$, Sebastian Jimenez ${ }^{1,2,3}$, Raquel Sanchez-Varo ${ }^{3,4}$, Victoria Navarro ${ }^{1,2,3}$, Laura Trujillo-Estrada, \\ Elisabeth Sanchez-Mejias ${ }^{3,4}$, Irene Carmona ${ }^{1,2,3}$, Jose Carlos Davila ${ }^{3,4}$, Marisa Vizuete ${ }^{1,2,3}$, Antonia Gutierrez ${ }^{3,4^{*}}$ \\ and Javier Vitorica ${ }^{1,2,3^{*}}$
}

\begin{abstract}
Background: Axonal pathology might constitute one of the earliest manifestations of Alzheimer disease. Axonal dystrophies were observed in Alzheimer's patients and transgenic models at early ages. These axonal dystrophies could reflect the disruption of axonal transport and the accumulation of multiple vesicles at local points. It has been also proposed that dystrophies might interfere with normal intracellular proteolysis. In this work, we have investigated the progression of the hippocampal pathology and the possible implication in Abeta production in young (6 months) and aged (18 months) PS1(M146L)/APP(751sl) transgenic mice.

Results: Our data demonstrated the existence of a progressive, age-dependent, formation of axonal dystrophies, mainly located in contact with congophilic Abeta deposition, which exhibited tau and neurofilament hyperphosphorylation. This progressive pathology was paralleled with decreased expression of the motor proteins kinesin and dynein. Furthermore, we also observed an early decrease in the activity of cathepsins $B$ and $D$, progressing to a deep inhibition of these lysosomal proteases at late ages. This lysosomal impairment could be responsible for the accumulation of LC3-II and ubiquitinated proteins within axonal dystrophies. We have also investigated the repercussion of these deficiencies on the APP metabolism. Our data demonstrated the existence of an increase in the amyloidogenic pathway, which was reflected by the accumulation of hAPPfl, C99 fragment, intracellular Abeta in parallel with an increase in BACE and gamma-secretase activities. In vitro experiments, using APPswe transfected N2a cells, demonstrated that any imbalance on the proteolytic systems reproduced the in vivo alterations in APP metabolism. Finally, our data also demonstrated that Abeta peptides were preferentially accumulated in isolated synaptosomes.

Conclusion: A progressive age-dependent cytoskeletal pathology along with a reduction of lysosomal and, in minor extent, proteasomal activity could be directly implicated in the progressive accumulation of APP derived fragments (and Abeta peptides) in parallel with the increase of BACE-1 and gamma-secretase activities. This retard in the APP metabolism seemed to be directly implicated in the synaptic Abeta accumulation and, in consequence, in the pathology progression between synaptically connected regions.
\end{abstract}

Keywords: Alzheimer's disease, PS1/APP transgenic model, Dystrophic neurites, Tau phosphorylation. Cathepsin activity, APP processing, Abeta production

\footnotetext{
*Correspondence: agutierrez@uma.es; vitorica@us.es

${ }^{3}$ Centro de Investigacion Biomedica en Red sobre Enfermedades

Neurodegenerativas (CIBERNED), Madrid, Spain

${ }^{1}$ Instituto de Biomedicina de Sevilla (IBIS), Hospital Universitario Virgen del Rocio,

Consejo Superior de Investigaciones Cientificas Universidad de Sevilla, Sevilla, Spain

Full list of author information is available at the end of the article
} 


\section{Background}

Alzheimer's disease (AD) is a proteinopathy characterized by the accumulation of aggregated extracellular amyloid-beta (Abeta, A $\beta$ ) peptides and intracellular hyperphosphorylated tau (revised in [1]). Concomitant with appearance of extracellular Abeta deposits, another central pathological feature of the disease is the early formation of amyloid plaque-associated neuritic changes in the form of dystrophic neurites, together with a selective loss of connections and neuronal groups. Dystrophic neurites, defined as thickened or irregular neuronal processes, are considered to be expression of a widespread alteration of the neuronal cytoskeleton. In $\mathrm{AD}$, dystrophic axons are particularly abundant in the hippocampal fiber systems originating from the subiculum, CA1, and the entorhinal cortex [2]. However the exact molecular mechanisms underlying the pathogenesis of $\mathrm{AD}$ remain to be elucidated.

Dystrophic neurites were characterized by the presence of numerous vesicles of multiple origins $[3,4]$. Several lines of investigation support the notion that defective autophagy process, a cellular catabolic mechanism essential for degradation of aggregated proteins and organelles, significantly contributes to $\mathrm{AD}$ pathogenesis [5-8]. Interestingly, autophagic compartments have been reported to participate in APP processing and A $\beta$ peptides production [9].

Abeta peptides, cytotoxic in their oligomeric state [10-13] derive from the sequential cleavage of APP by beta- and gamma-secretases $[14,15]$. Although the exact intracellular localization of APP processing is unknown, the autophagic and endocytic pathways could be both involved in precursor protein (APP) processing and Abeta generation. In this sense, BACE-1 and gammasecretase complex have been detected in many cellular locations, including early and late endosomes [16], autophagic vacuoles [17-19] and lysosomes [20]. On the other hand, the Abeta degradation, in vivo, could be mediated by several proteases, as neprilysin, IDE, and several cathepsins as B, D and E [21]. Abnormal processing of APP or Abeta accumulation in AD could be related to several mechanisms, including excessive production, abnormalities in transport, alteration of autophagic and endosomal pathways, and deficits in its degradation through the lysosome or the ubiquitinproteasome system (UPS) [22-24]. In fact, accumulation of autophagic vacuoles (AVs) has been observed in brains from AD patients [3,19] and in PS1/APP mice after Abeta deposition [17,19,25]. Moreover, the AVs were principally accumulated within dystrophies and could reflect impairment in AVs clearance in AD brains [5]. In this sense it has been reported that enhancing lysosomal cathepsin activity ameliorates Abeta toxicity [26] and restoring the autophagy-lysosomal pathway (by deletion of cystatin B) reduced amyloid load and rescued memory performance [9].

In the present work we investigated how the possible age-related relationship between aberrant Abeta generation and dysfunctions in axonal cytoskeleton as well as in lysosomal and proteasomal systems, manifested in our PS1/APP AD model. We proposed that the decrease in lysosomal proteolytic activities was implicated in increased Abeta production. Abnormal accumulation of Abeta could aggravate the axonal and cytoskeleton abnormalities linked to the pathology of AD.

\section{Results}

The age-dependent increase of neuritic dystrophies was paralleled by phosphorylation of cytoskeletal proteins and decrease in motor proteins

APP-positive dystrophic neurites represented an early pathology in our PS1/APP model [17]. These dystrophies were of axonal origin and, at early ages, were located exclusively surrounding congophilic Abeta plaques. It was also known that Abeta load increased with aging in this and most AD models [27]. Thus, we have first evaluated the progression of the APP-positive dystrophy formation from early (4-6 months) to late (12-18 months) ages. As expected, the number of APP-positive dystrophies, surrounding Abeta plaques, increased significantly in 12-18 month cohort (Figure 1A), paralleling the increase in plaque size and number (Figure 1A and [17]). Furthermore, according with previous data, the dystrophic neurites were predominantly concentrated surrounding the congophilic Abeta plaques at all ages.

The presence of aberrant hyperphosphorylated cytoskeletal proteins is one of the major pathological hallmarks of AD [28]. Furthermore, hyperphosphorylated neurofilaments and tau seemed to overlap with senile plaques in $\mathrm{AD}$ patients and models (unpublished data, see also $[17,28,29])$. Thus, hyperphosphorylated cytoskeletal proteins could also be implicated in the progression of the pathology in our PS1/APP model. To determine this possibility, we tested the neurofilaments (using SMI antibodies) and tau phosphorylation (AT8 and AT100 epitopes) in 6- and 18 months PS1/APP. As we described previously [17], 6-month-old PS1/APP mice displayed only minor modifications. In fact, as compared with age-matched WT mice, neurofilament (heavy and medium chains; $\mathrm{H}, \mathrm{M}$ ) phosphorylation (calculated as ratio between phospho and non-phosphorylated neurofilament) exhibited no apparent modifications at this age (see Figure 1B). Only the levels of AT8 epitope were slightly but significantly increased. However, 18-monthold PS1/APP mice displayed advance cytoskeletal pathology. As shown (Figure 1B), neurofilament heavy and medium chains were hyperphosphorylated (mostly due 


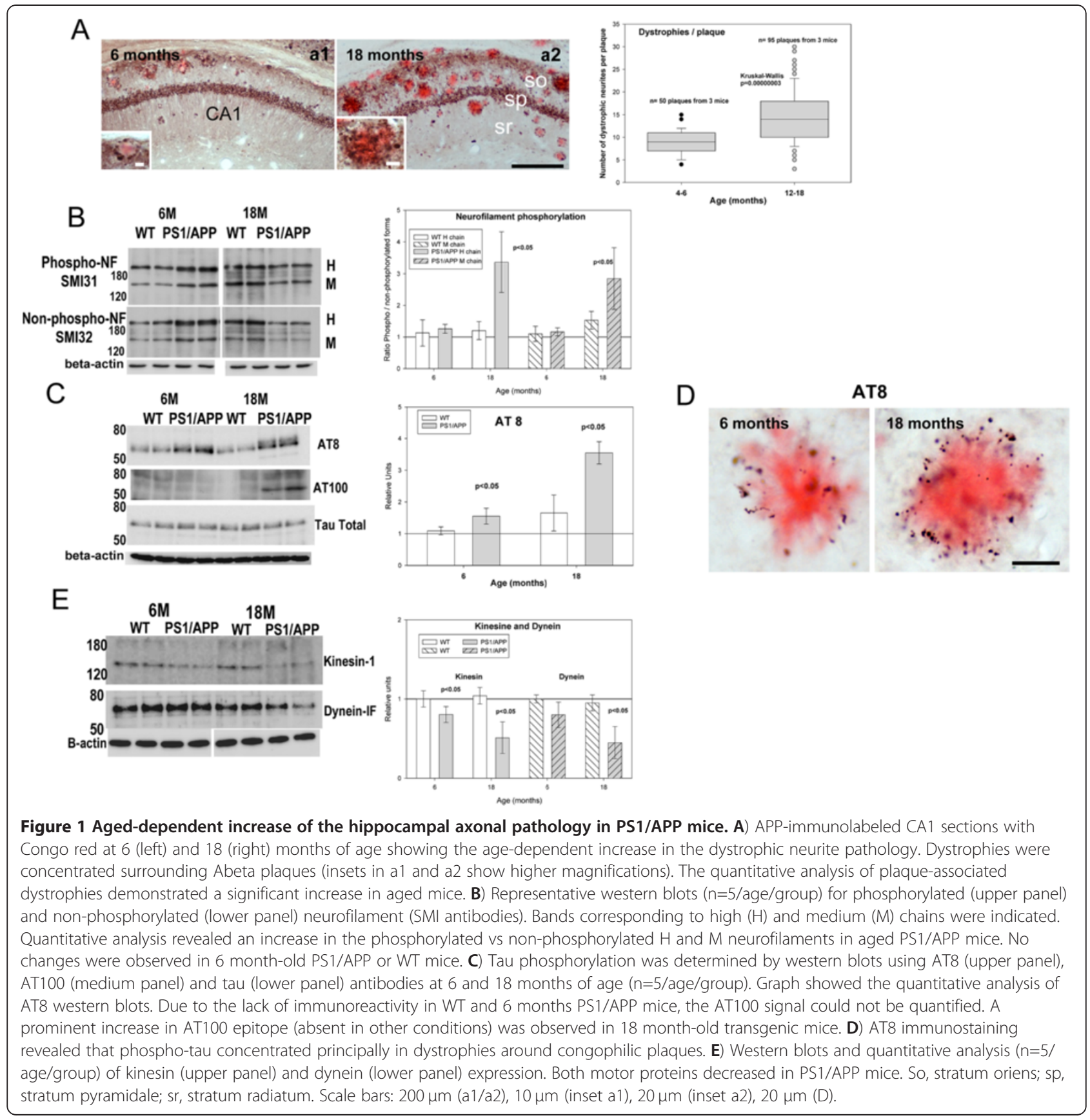

to a decrease in the non-phosphorylated forms). In agreement with this observation, both AT8 and, more prominently, AT100 tau phosphoepitopes (Figure 1C) were increased in 18 month-old PS1/APP. The presence of hyperphosphorylated tau was further confirmed by immunohistochemistry. Tau-reactive (AT8) dystrophic neurites, localized surrounding amyloid plaques, were detected since early ages (Figure 1D).

To further evaluate whether microtubule vesicular transport might be compromised in PS1/APP mice, we have assessed the levels of kinesin-1 and dynein motor proteins. As previously reported [17], 6 month-old PS1/ APP mice showed a modest reduction on both proteins and, in accordance with the advance pathology, the levels of both motor proteins were dramatically reduced in 18 months PS1/APP mice (Figure 1E).

These data confirmed and extended our previous observation in this model, at early ages, and demonstrated the existence of a clear age-dependent axonal pathology implicating cytoskeletal and motor proteins. 


\section{The age-dependent progression of the neuritic pathology was associated to an impairment of proteolysis mechanisms}

It has been reported that axonal dystrophy could be produced by inhibition of the lysosomal proteolysis [30,31] or by axonal transport deficiencies [32]. However, axonal transport was also essential for the correct lysosomal maturation and intracellular protein degradation [33]. Thus, the formation and the age-dependent increase in neuritic dystrophies could be cause or consequence of a progressive reduction of the intracellular proteolytic processes. Theoretically, an impairment on either proteaso$\mathrm{mal}$ and/or autophagic/lysosomal route, in the PS1/APP model, should be reflected by the accumulation of ubiquitinated proteins and/or the autophagic maker LC3-II. In fact, our data (Figures 2A and B) clearly demonstrated the existence of a marked and early accumulation of both ubiquitinated proteins and LC3-II in hippocampal samples from PS1/APP mice. This accumulation was observed since early ages (6 months of age), increased significantly in aged PS1/APP mice (18 months) and was not observed at 2 months of age, before plaque deposition (not shown). On the contrary, WT mice displayed absolutely no changes at these ages. These data were further confirmed by immunohistochemistry experiments. As shown, (Figure 2C, c1 to c6), the LC3 immunoreactivity was principally located in the somata and apical dendrites of principal neurons whereas ubiquitin immunostaining (Figure 2D, d1 to d6) was mainly located at the cell bodies (see Figure 2D, d2 inset). Furthermore, most (if not all) Abeta plaques (stained with Congo Red) were surrounded by dystrophies, LC3 or ubiquitin immunopositive, both at 6 months and more patently at 18 months of age.

Although the accumulation of LC3-II could reflect both, induction in the autophagy route or decrease in the autophagosome degradation, the presence of ubiquitinated proteins in a similar localization of LC3, surrounding Abeta plaques, strongly suggested the existence of a decrease in autophagosome degradation. Among different causes, the decrease in autophagosome degradation could reflect a decrease in the lysosomal activity. Thus, we next evaluated the lysosomal and proteasomal activity by determining the cathepsins, B and D, activities and the proteasomal chymotrypsin-like activity. As shown (Figure 2E), both cathepsin B and D activities decreased since relatively early ages. Young (6 months) PS1/APP displayed a consistent $(-39.21 \pm 18.84 \% ; n=5$, $\mathrm{p}<0.05 ;-44.15 \pm 13.51 \%, \mathrm{n}=3, \mathrm{p}<0.05$; for cathepsin $\mathrm{B}$ and $\mathrm{D}$, respectively) decrease (as compared with age matched WT) whereas 18 month-old PS1/APP mice displayed a further diminution $(-72.50 \pm 4.2 \% ; \mathrm{n}=4$, $\mathrm{p}<0.05 ;-55.45 \pm 6.7, \mathrm{n}=3, \mathrm{p}<0.05$, respectively). No changes were observed before plaque deposition (at 2 month-old, not shown). On the other hand, the proteasomal activity (Figure 2F) also displayed a slight, and not significant diminution at 6 -months $(-20.4 \pm 12.3 \%, \mathrm{n}=4)$ followed by a more pronounced inhibition in aged PS1/APP mice $(-45.5 \pm 15.6 \% ; \mathrm{n}=4 ; \mathrm{p}<0.05)$. No differences between WT and PS1/APP were observed before the plaque deposition (2 months of age, not shown) and no inhibition was observed in 18 months WT mice.

Consistent with the decrease in lysosomal activity, we also observed a significant reduction in the mature forms of both cathepsins B and D in PS1/APP mice (Figures $3 \mathrm{~A}$ and $\mathrm{B}$ ) and an accumulation of the lysosomal protein lamp 1 (Figures 3C),at 6 and 18 months. Furthermore, this accumulation of lysosomal proteins seemed to be localized in dystrophies surrounding Abeta plaques, as demonstrated by immunohistochemistry analysis of lamp 2 protein (Figure 3D). These data revealed the existence of a lysosomal dysfunction in PS1/APP mice after plaque deposition. In this sense, it has been recently reported [6] that PS1 mutations affected the correct maturation of the V0a1 subunit of the vATP-ase and the lysosomal acidification. However, in our model, we observed an accumulation of the mature form of V0a1 protein (Figure 3E), similar to lamp 1 protein (compare Figures $3 \mathrm{C}$ and E). Furthermore, 6-month-old homozygous PS1M146L transgenic mice displayed no alterations on cathepsin B activity (not shown).

The amyloidogenic APP processing and both BACE-1 and gamma-secretase activities were increased in aged PS1/ APP mice

Data so far demonstrated the existence of a progressive age-dependent neuritic (probably axonal) pathology in the PS1/APP model that affected the intracellular proteolytic systems. We next evaluated whether this progressive pathology could affect the amyloidogenic APP processing. As shown (Figure 4A), the mature hAPPfl (visualized as two bands, corresponding with the mature and immature forms of the transgenic hAPP) significantly increased in the hippocampus of 18 month tg mice, as compared with 6 month-old animals $(2.01 \pm 0.04$; $\mathrm{n}=6 ; \mathrm{p}<0.05)$, Also, a significant increase in the ratio mature/immature form of the hAPP was observed (data not shown). However, no differences in mRNA expression of the transgenic hAPP were detected between 2 and 18 months (data were normalized to the expression levels observed in 6 months PS1/APP, $\mathrm{n}=6$ for each age, $1.12 \pm 0.15,1.0 \pm 0.27,1.33 \pm 0.29$ and $1.23 \pm 0.48$ for 2,6 , 12 and 18 month PS1/APP, respectively).

The APP proteolytic fragments C83 (alpha-CTF) and C99 (beta-CTF) are products from alpha- or betasecretase processing, respectively, and substrates for gamma-secretase complex. As also shown in Figure 4A, the levels of C99 showed a clear age-dependent increase, 


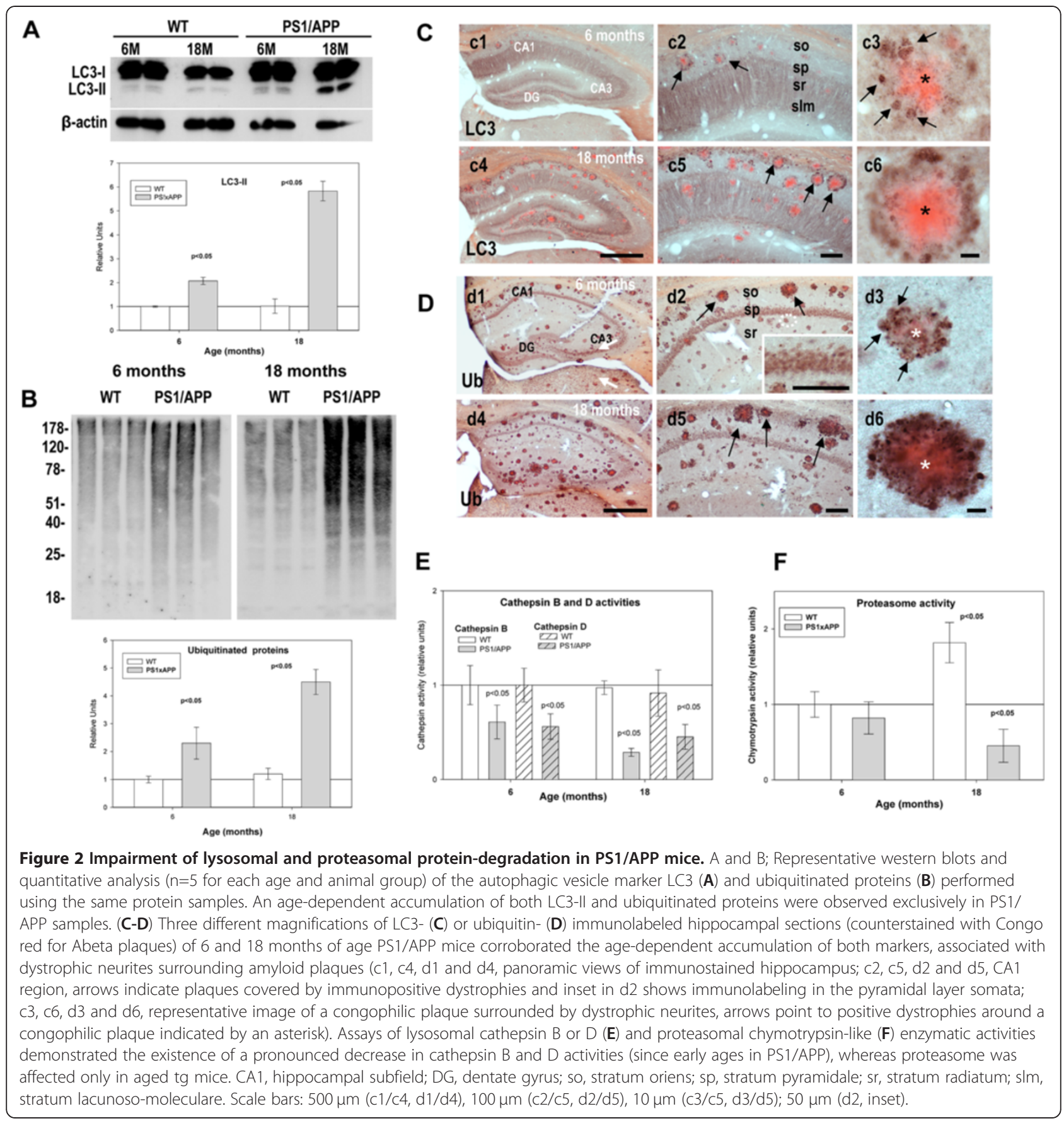

from 6 to 18 month in PS1/APP mice whereas C83 levels were low (respect to C99) and remained practically unaltered during aging (see also Figure 5). Together with the accumulation of APP and APP-fragments, we also observed an increase in the levels of both BACE-1 and PS1 proteins. As shown, Figure 4B, the mature (and immature) form of BACE-1 was increased in 18-month-old PS1/APP mice (as compared with 6 months) whereas no differences in mRNA levels were observed (data were normalized by the expression of 6-month-old WT mice, $\mathrm{n}=5$ for each age and genotype: 6 months: $1.00 \pm 0.08$ vs $0.88 \pm 0.24 ; 12$ months: $1.39 \pm .19$ vs $1.10 \pm 0.12 ; 18$ months: $1.29 \pm 0.20$ vs $1.33 \pm 0.27$; for WT and PS1/APP, respectively). As expected, BACE-1 was preferentially accumulated within dystrophies, surrounding Abeta plaques (Figure 4C). Furthermore, this alteration in BACE-1 level was also reflected by a higher BACE-1 enzymatic activity (Figure 4E). In parallel with these 


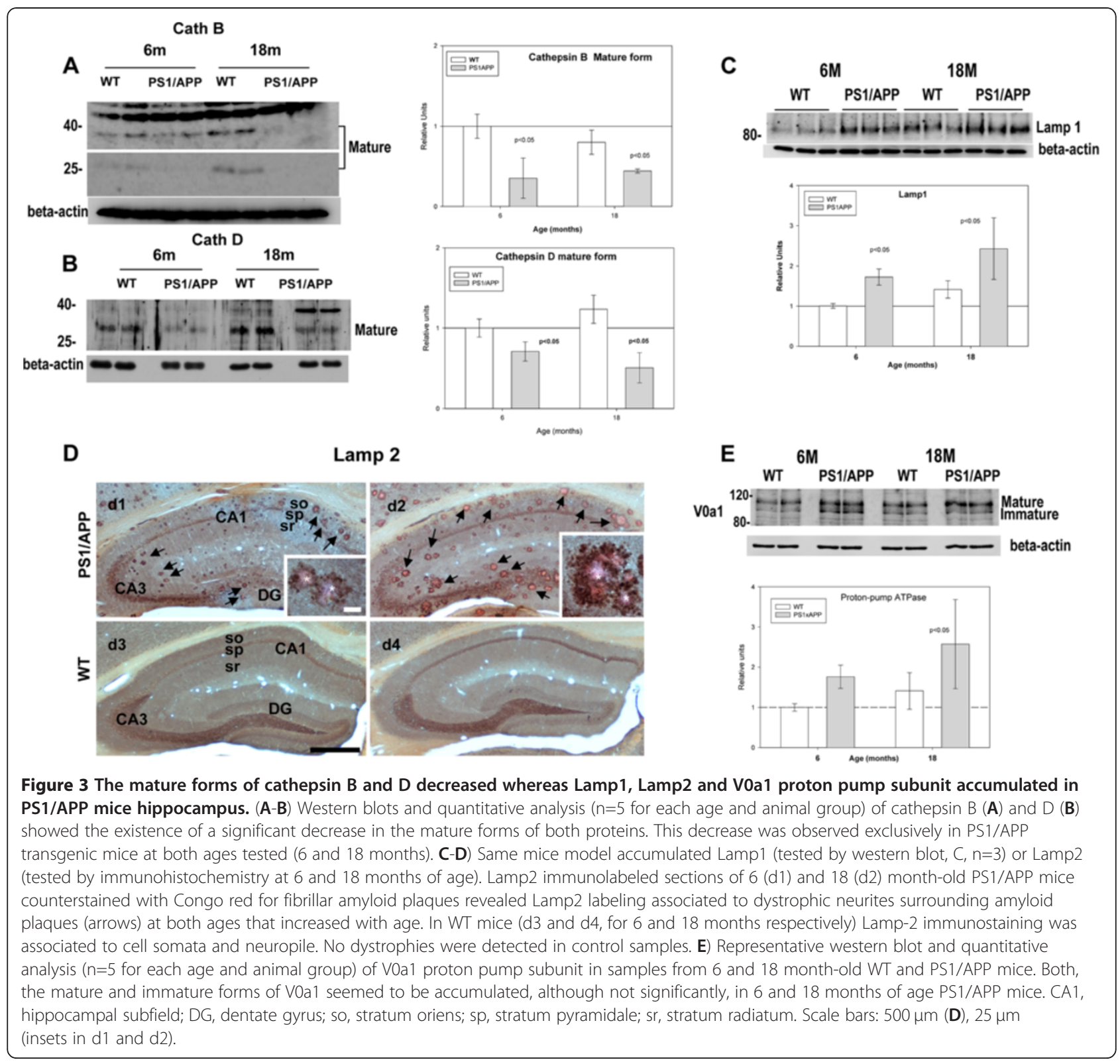

observations, the PS1-ctf fragment and PS1fl (practically undetectable in WT and at early ages in PS1/APP mice, Figure 4D) were also accumulated in aged PS1/APP mice (Figure 4D), in absence of variation in the transgene expression (data were normalized to expression levels detected in 6 months PS1/APP, $\mathrm{n}=6$ for each age, $1.06 \pm 0.45,1.0 \pm 0.69,1.33 \pm 0.62$ and $1.03 \pm 0.82$ for $2,6,12$ and 18 month PS1/APP, respectively). Although gammasecretase is a multimeric protein and the increase in a single subunit could not directly reflect a parallel increment in the mature complex, it is of note that PS1terminal fragments were exclusively generated when PS1fl was incorporated into the mature complex (see
[34]). Thus, these data were consistent with an agedependent increase in gamma-secretase. In fact, the gamma-secretase activity, determined as the rate of AICD production using fresh membranes isolated from different ages (in consequence, the substrate was the endogenous APP-CTF fragments, presented at each age) displayed a consistent increase in the aged PS1/APP samples (Figure 4F). It should be noted that, under these experimental conditions, we cannot discriminate if the increase in gamma-secretase activity was reflecting the accumulation of PS1-ctf or just an increase in substrate (C99 fragment, predominantly). Independently, the aged PS1/APP mice displayed an increased C99 processing capacity. 


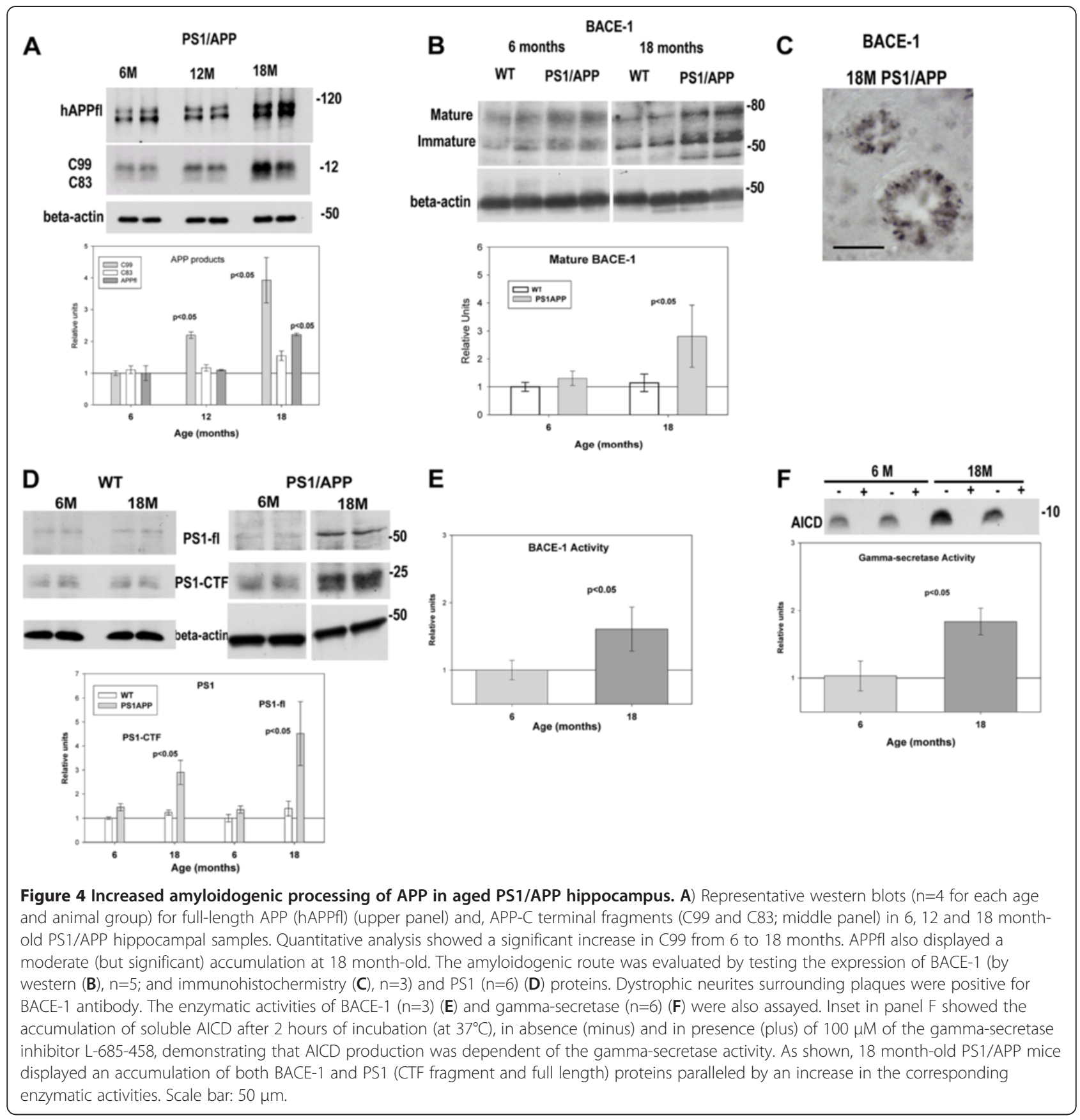

Inhibition of lysosome increased APP-processing and Abeta accumulation in N2aAPPswe cells

We next evaluated, in vitro using APPSwedish transfected N2a cells [35], whether the APP metabolism was indeed affected by the inhibition of the intracellular proteolysis. For these experiments, the lysosomal or proteasomal/lysosomal activities were inhibited by the addition of Chloroquine $(10 \mu \mathrm{M})$ or MG132 $(5 \mu \mathrm{M})$. As expected, both lysosomal and/or proteasomal inhibition produced the accumulation of ubiquitinated proteins and the autophagosomal marker LC3-II (Figure 5A). Using the same protein extracts, we next tested whether the inhibition of proteasomes and/or lysosomes was reflected by alterations of the APP metabolism. As shown, both inhibitors produced a clear accumulation of APP-CTFs in APP N2a cells. In fact, C99 fragment and, more relevant, intracellular monomeric Abeta were accumulated after either treatment (Figure 5B). Furthermore, we also observed a parallel accumulation of BACE-1 and PS1-cft protein (Figure 5C). Therefore, these in vitro experiments demonstrated that the inhibition of lysosomal or proteasomal degradation processes produced the 


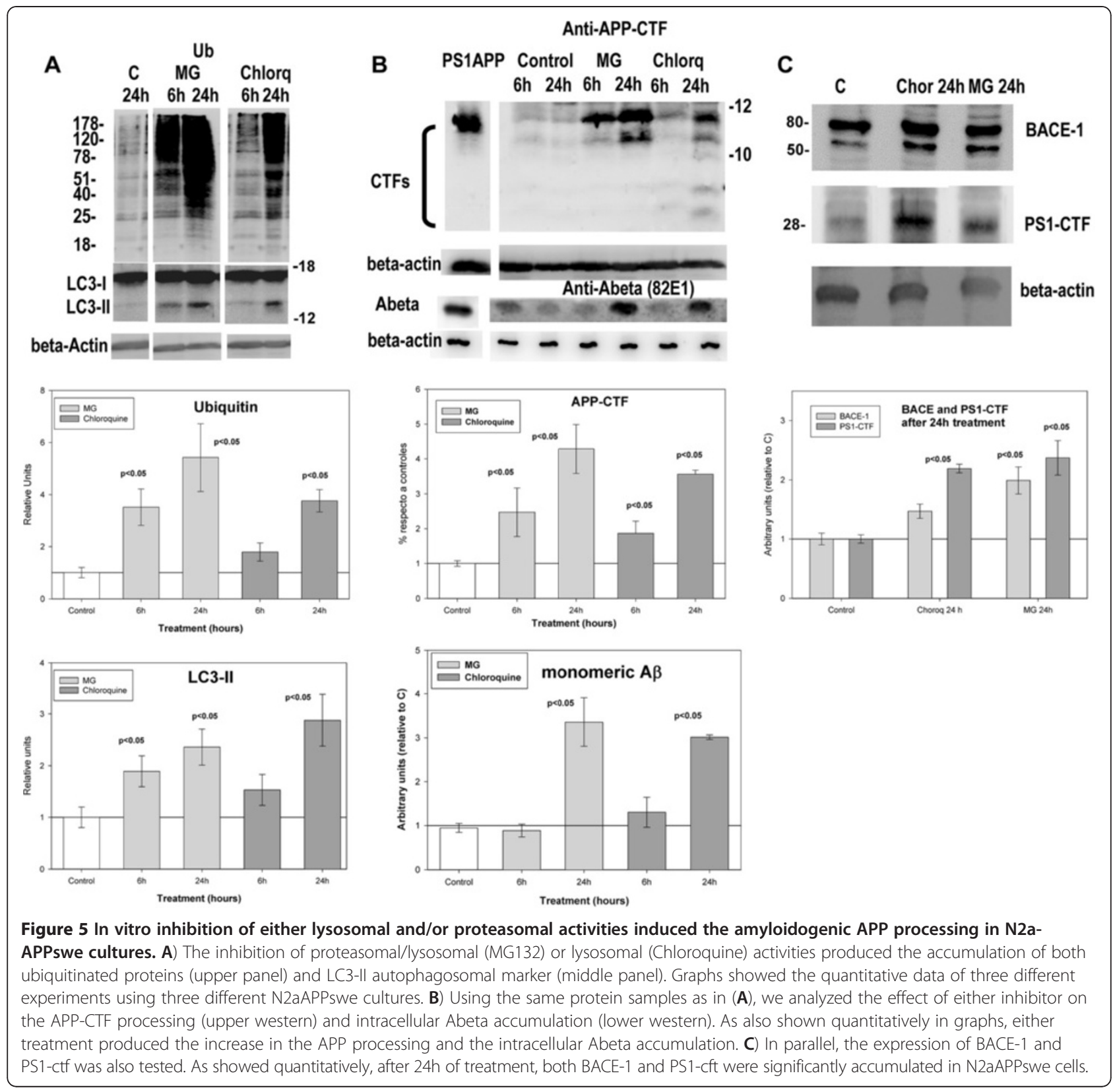

accumulation of APP fragments and Abeta production, in parallel with BACE-1 and PS1-ctf proteins. These data demonstrated that any misbalance in the correct intracellular proteolysis could induce the accumulation of APP products and, in consequence, increased the production of Abeta peptide.

\section{Age-dependent increase in Abeta accumulation in isolated presynaptic terminals (synaptosomes)}

Finally, we also tested whether the observed agedependent deficiencies in cytoskeletal proteins, lysosomal activity and APP-metabolism were reflected by modification of the APP fragment distribution in isolated synaptosomes. If the neuritic pathology in this model was predominantly, although not exclusive, of axonal origin, the observed modifications should produce the accumulation of APP-derived peptides (including Abeta) at the presynaptic terminals. In fact, we have recently reported the existence of presynaptic terminals containing multiple autophagic vesicles in PS1/APP mice [17]. To test this possibility, the homogenates were fractionated into microsomal and synaptosomal fractions. The microsomal fraction contained a heterogeneous population of vesicles of different origins whereas synaptosomes were principally enriched in presynaptic terminals. 
We first compared the distribution of LC3-II protein, as a marker of autophagosomes, between microsomes and synaptosomes. As shown (Figure 6A, a1), in WT mice the LC3-II was abundant in microsomes whereas it was scarce in synaptosomes at any age tested (see also [17]). As expected, the LC3-II levels were higher in PS1/ APP mice, as compared with WT, and increased with age in both fractions (Figures 6A and B). Thus, these data indicated the accumulation of autophagic vesicles at the presynapses [17] and also corroborated the existence of transport defects in PS1/APP mice.

We next analyzed the distribution of APP CTFs (C99 and C83) and Abeta between both fractions (Figure 6A, a2-4). Although the level of C99 increased clearly with age (in agreement with our previous data), the C99 content was patently higher in microsomes than in the synapsomal fraction. This preferential distribution was in agreement with the accumulation of BACE-1 in dystrophic neurites (Figure $4 \mathrm{C}$ ) and the relative abundance of BACE-1 in microsomes (vs synaptosomes, data not shown). However, in spite of the large C99 accumulation, the monomeric Abeta peptide was scarce in microsomes and was preferentially accumulated at the synaptosomal fractions. It is noteworthy that, at early ages, synaptosomes accumulated low amount of monomeric Abeta (see Figures 6 a3, a4, D and E), whereas, at late ages, the monomeric Abeta peptide was highly concentrated at the synaptosomal fractions (63.6 \pm 7.5 fold as compared with 6 months, $n=4$; Figure 5D).

It could be argued that synaptosomal Abeta were of extracellular origin, due to contamination with plaques or by internalization during homogenization. To ascertain the intrasynaptosomal origin we have first tested whether the Abeta in the synaptosomal fractions was due to plaque

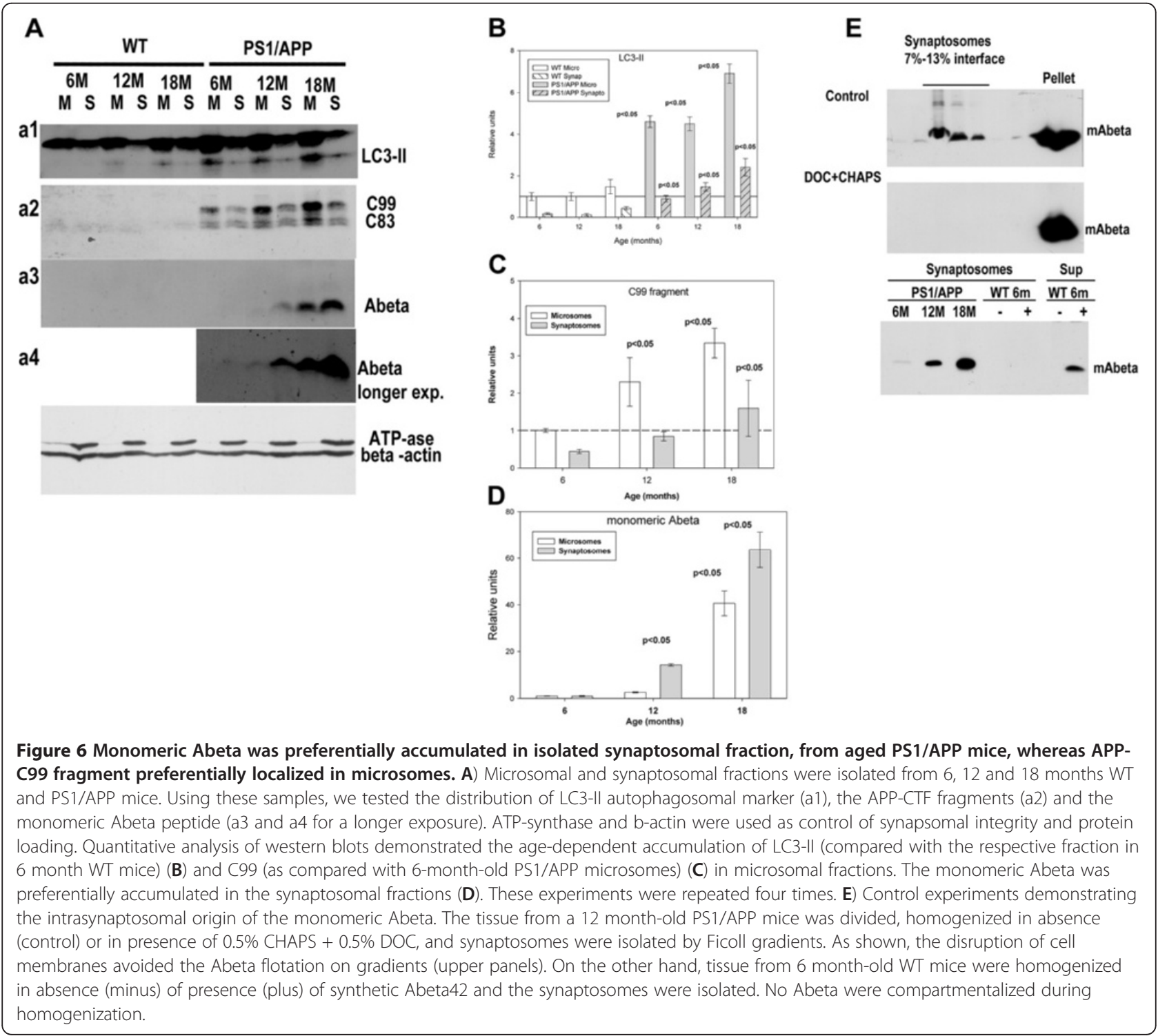


contamination. As shown in Figure 6E (upper panels), the disruption of cellular membranes and the formation of synaptosomes, by homogenization of the tissue in presence of mild detergents (CHAPS plus deoxycholate), completely avoided the presence of Abeta on the synaptosomal fractions of the Ficoll-gradients. Second, the possible extracellular origin of Abeta, due to its compartmentalization on synaptosomes during homogenization, was tested by adding synthetic monomeric Abeta42 to WT samples in the homogenization buffer. As shown, Figure 6E lower panel, the synthetic Abeta was not recovered on the synaptosomal fractions of WT mice whereas it was clearly detectable on the soluble fractions. These control experiments demonstrated the intrasynaptosomal origin of Abeta.

\section{Discussion}

In this work, we studied the progression of hippocampal neuronal pathology, in the PS1M146L/APP751SL model, that connects cytoskeleton and protein degradation dysfunction with dystrophy formation and synaptic Abeta production. As we reported previously, this model displayed the formation of axonal dystrophies, associated to extracellular Abeta deposition since early ages [17]. These dystrophies accumulated numerous vesicles of, among different origins, autophagic/lysosomal nature. Also, the axonal pathology was associated with the presence of aberrant presynaptic terminals in close proximity to Abeta plaques. In agreement with others [36-38] we observed that extracellular Abeta, probably by increasing the local calcium concentration, might produce cytoskeletal abnormalities that could induce transport defects (see also [39-43]). In fact, data presented in this work demonstrated the existence of a progressive increase in neurofilaments and tau hyperphosphorylation (SMI31, AT8 and AT100 epitopes). This increase was prevalently observed in dystrophies, surrounding the Abeta plaques. In conjunction with this apparent cytoskeletal dysfunction, we also observed a decrease in the levels of kinesin and dynein motor proteins. Taken together, these data strongly suggest the existence of a progressive, agedependent, disorganization of the axonal cytoskeleton, which could impair the normal axonal transport, at local points in contact with extracellular Abeta deposits, (see also $[25,43])$. Furthermore, our data also demonstrated the accumulation of LC3-II and ubiquitinated proteins, principally at dystrophies. Whereas these observations could be interpreted as a simple accumulation of autophagosomes/lysosomes due to transport defects, our data also demonstrated the existence of a marked inhibition of the intracellular proteolytic activities. In fact, we observed a profound decrease in the cathepsin B and D activities and, in a minor extent, the proteasomal chymotrypsin activity. In parallel, we also observed a reduction in the mature forms of both cathepsins B and D in PS1/APP samples. The reasons that determined this marked and early proteolytic inhibition are unknown. It has been proposed that FAD mutations in PS1 impaired the maturation of V0a1 subunit of the vATP-ase [6]. However, as mentioned (see results), in our model, the V0a1 subunit displayed no apparent defects on its maturation. Furthermore, 6-month-old PS1M146L transgenic mice displayed no variations on cathepsin $B$ activity. Thus, the observed decrease in cathepsin B and D activities seemed to be independent of the proton pump maturation (see also [44]). Nevertheless, our data were indeed compatible with defects on lysosomal acidification and/or maturation. In this sense, it has been also proposed that axonal transport was crucial for lysosomal maturation and function [33]. Thus, in our AD model, the cytoskeletal disorganization (probably mediated by extracellular Abeta and calcium misbalance) could also impair the lysosomal maturation (reflected by a decrease in the mature forms of both cathepsins tested) and, in consequence, the proteolytic function (decrease in the cathepsin activities). Further experiments should be done to ascertain this point.

We also analyzed the consequences of this neuritic pathology on APP processing and Abeta generation. In this sense, the overexpression of cathepsin B [45], the enhancement of cathepsin activities [9] or the positive lysosomal modulation [26] reduced the Abeta accumulation, the synaptic deficiencies and restored the cognitive function in transgenic mice. Thus, the progressive decrease of cathepsin activities and, in a minor extent, proteasomal activity, observed in our model, could be paralleled by an increase in the amyloidogenic APP processing. In fact, the observed agedependent accumulation of hAPPfl and C99, together with the increase in BACE-1 and PS1-ctf proteins and their enzymatic activities, confirmed this proposition. Furthermore, our in vitro experiments also corroborated the rapid and progressive accumulation of APP derived C-terminal fragments, intracellular Abeta and both BACE-1 and PS1-ctf proteins after lysosomal and/or proteasomal inhibition (see also [46,47]). Therefore, based on these data, it is tempting to speculate that the formation of axonal dystrophies, probably due to the presence of extracellular Abeta [48], might produce a decrease in the intracellular proteolysis. This was paralleled by the accumulation of APP derived fragments inducing, in consequence, the production of higher amount of Abeta peptides (see also [49]). This self-progressing pathological scenario could be implicated in the progressive increase of Abeta and BACE-1 observed in AD patients (data not shown; see also [50]) and in the expansion of the pathology (see below). 
Of note, our data also demonstrated the existence of a preferential accumulation of Abeta peptides in isolated synaptosomal fractions. Whereas this preferential accumulation could reflect the high gamma-secretase activity at the presynaptic terminals (data not shown but see [51]), these data also indicated that Abeta peptides were produced in compartment(s) different to, or in addition to, the autophagic vesicles [52]. This proposition was based on the observation that LC3-II, an autophagic marker, was preferentially concentrated in the microsomal fractions and it was scarce in synaptosomes. Although autophagic vesicles were indeed concentrated in pathological presynaptic terminals [17], the clear disproportion between LC3-II and Abeta in microsomes and synaptosomes, at all ages tested, strongly indicated a different compartmentalization. In this sense, it has been recently proposed that Abeta was synaptically produced and secreted from endosomal compartment [53]. Independently of the intracellular compartment, the synaptic production of Abeta peptides, observed in this work, could be implicated in the synaptic dysfunction in $A D$ patients and in the pathological progression between synaptically connected areas. In this sense, it is widely accepted that the severity of the disease correlated better with the synaptic dysfunction rather than the plaque load. Thus, the age-dependent accumulation and, probably, release of Abeta peptides by presynapses could be directly implicated in the dendritic spine alterations observed in AD patients and in AD models. Furthermore, recent publications have been highlight the progression of Abeta [54,55] and tau [56,57] pathology between synaptically connected regions. In this sense, we have also reported the existence of a preferential Abeta deposition, microglial activation and neurodegeneration of principal neurons in layers V-VI of the entorhinal cortex [58]. However, these particular pyramidal cells did not express the transgenic hAPP and, in consequence, did not produce Abeta peptides. Thus, the presynaptic accumulation of Abeta peptides, reported here, might be implicated in the Abeta deposition and pathological spreading from Abeta producing region/layer into other brain regions.

In sum, our data demonstrated the existence of a progressive, age-dependent, cytoskeletal pathology (probably due to the extracellular Abeta deposition) that could be implicated in a reduction of the intracellular proteolytical processes. This impairment was associated to a progressive accumulation of APP derived fragments (and Abeta peptides) according with the increase of BACE-1 and gamma-secretase activities. This retard in the APP metabolism seemed to be directly implicated in the synaptic Abeta accumulation and, in consequence, in the pathology progression between synaptically connected regions.

\section{Methods}

\section{Transgenic mice}

Generation and initial characterization of PS1M146L/ APP751sl (PS1/APP) tg mice has been reported previously $[10,58,59]$. Heterozygous PS1/APP double tg mice (C57BL:6 background) were generated by crossing homozygous PS1 tg mice with heterozygous Thy1-APP751SL mice. Only male mice were used in this work. Agematched non-transgenic male mice (WT) of the same genetic background (C57BL:6) were used as controls.

Mice were first anesthetized with sodium pentobarbital $(60 \mathrm{mg} / \mathrm{kg})$, the hippocampi were dissected and immediately frozen and stored at $-80^{\circ} \mathrm{C}$ until use. For immunohistochemistry, anesthetized mice were perfused transcardially with a paraformaldehyde-based solution (see details below). All animal experiments were performed in accordance with the guidelines of the Committee of Animal Research of the University of Seville (Spain) and the European Union Regulations.

\section{RNA and total protein extraction}

Total RNA from mice hippocampi or cultured cells was extracted using Tripure Isolation Reagent (Roche) as described previously $[10,11,27,58,59]$. After isolation, RNA integrity was assessed by agarose gel electrophoresis. The yield of total RNA was determined by measuring the absorbance $(260: 280 \mathrm{~nm})$ of isopropanol-precipitated aliquots of the samples. The recovery of RNA was comparable in all studied groups (1.2-1.5 $\mu \mathrm{g} / \mathrm{mg}$ of tissue).

The protein pellets, obtained using the Tripure Isolation Reagent and isopropanol-mediated precipitation, were resuspended in $4 \%$ SDS and $8 \mathrm{M}$ urea in $40 \mathrm{mM}$ Tris- $\mathrm{HCl}, \mathrm{pH} 7.4$ and rotated overnight at room temperature to get complete protein solubilization.

\section{Reverse transcription and real-time RT-PCR}

Retrotranscription (RT) was performed using random hexamers, $4 \mu \mathrm{g}$ of total RNA as template and HighCapacity cDNA Archive Kit (Applied Biosystems) following the manufacturer recommendations [10,27]. For real time RT-PCR, commercial Taqman ${ }^{\mathrm{Tm}}$ probes (Applied Biosystems) were used for amplification. Alternatively, SYBRgreen dye and designed specific primers were used for amplification of human APP751 (forward: 5'-GGATATGAAGTTCATCATCA-3'; reverse: 5'TCACTGTCGCTATGACAACA-3'), and human PS1 (forward: 5'-TGGCTCATCTTGGCTGTG-3'; reverse: 5'-ACCAGCATACGAAGTGG-3'). PCR reactions were carried out using either ABI Prism 7000 or $7900 \mathrm{HT}$ sequence detector systems (Applied Biosystems). A standard curve was first constructed for every assay, using increasing amounts of cDNA. In all cases, the slope of the curves indicated optimal PCR conditions (slope 3.2-3.4). The cDNA levels of the different mice were determined 
using GAPDH as housekeeper. Therefore, GAPDH amplification was done in parallel with the gene to be analyzed, and this dada used to normalize target gene results.

Independent of the analyzed gene, results were always expressed using the comparative $\mathrm{Ct}$ method, following the Bulletin number 2 from Applied Biosystems. As a control condition, we selected 6-month-old WT mice. In consequence, the expression of all tested genes, for all ages and mouse strains, was referenced to the expression levels observed in 6-month-old WT mice.

\section{Western blot}

Western blots were performed as described [60]. Briefly, 5-20 $\mu \mathrm{g}$ of proteins from the different samples were loaded on $16 \%$-SDS-tris-tricine-PAGE or 12\%-SDS-trisglycine-PAGE and transferred to nitrocellulose (HybondC Extra; Amersham).

After blocking, using 5\% non-fat milk, membranes were incubated overnight, at $4^{\circ} \mathrm{C}$, with the appropriate antibody: phospho-neurofilament (clone SMI-31; 1:1,000; Abcam), total-neurofilament (clone SMI-32; 1:1000; Abcam), phospho-Ser199:202-Thr205-PHF-tau (clone AT8; 1:1000; Pierce), phospho-Thr212-Ser214-PHF-tau (clone AT100; 1:1,000; Innogenetics), kinesin-1 heavy chain (1:1,000; Abcam), dynein-1 intermediate chain (1:1000; Millipore), ATP-synthetase-Beta (1:1000; BD Transduction Laboratories), Abeta peptide (clone 6E10; 1:5000; Signet), APP C-terminal (1:6000; Calbiochem), PS1 C-terminal (1:2000; Millipore), BACE-1 (1:1000; Abcam), V0a1-proton-pump subunit (1:1000; Synaptic Systems), LC3B (1:1000; Cell Signaling), cathepsin B (1:1000, Santa Cruz); cathepsin-D (1:5000; ABFrontier Co. Ltd), Lamp-1 (1:1000; Developmental Studies Hybridoma Bank; University of Iowa), ubiquitin (1:1000; Sigma-Aldrich) and Beta-actin (1:5000; Sigma-Aldrich). Membranes were then incubated with the corresponding horseradish-peroxidase-conjugated secondary antibody (Dako, Denmark) at a dilution of 1:8000. Each blot was developed using the ECL-plus detection method (Amersham).

For quantification, the scanned (Epson 3200) images were analyzed using PCBAS program. For normalization purposes, proteins were first estimated by Lowry and protein loading corrected by beta-actin. The intensity of bands from 6-month-old WT or PS1/APP (Figures 4A, $\mathrm{E}$ and F; Figures $5 \mathrm{C}$ and $\mathrm{D}$ ) mice were averaged and considered as 1 relative unit. All other data were then normalized by the specific signal observed in 6-month-old WT or PS1/APP group or negative control for "in vitro" experiments.

\section{Enzymatic activity determination}

BACE-1, Cathepsin B and D activities were determined using commercial kits (R\&D Systems, Germany;
Calbiochem, Germany and Sigma-Aldrich, respectively) following the manufacturer instructions. Briefly, fresh hippocampal samples were homogenized in the buffer supplied by the manufacturer or in PBS (for proteasome activity), centrifuged at 10,000xg (15 min at $\left.4^{\circ} \mathrm{C}\right)$ and the supernatant $(100-200 \mu \mathrm{g}$ of protein per assay) was used. BACE-1 and cathepsin B and D activities were determined using substrates provided by the manufacturer

Proteasome chymotrypsin-like activity was determined as described [61]. Briefly, soluble fractions $(30-50 \mu \mathrm{g}$ of protein per assay) were diluted in $50 \mu \mathrm{M}$ reaction substrate Suc-Leu-Leu-Val-Tyr-aminomethylcoumarin (AMC) (Sigma-aldrich), 0.1mM EDTA, 5mM DTT, 0.01\% (w:v) CHAPS; $100 \mathrm{mM} \mathrm{NaCl} ; 1 \%$ (v:v) Glycerol, $50 \mathrm{mM}$ HEPES-KOH pH 7.5. Duplicated reactions were placed in a 96-well black polystyrene microplate (BD Transduction Labs.) and incubated at $37^{\circ} \mathrm{C}$. Fluorescence was determined at excitation $360-380 \mathrm{~nm}$ and emission $460-480 \mathrm{~nm}$.

For each enzymatic assay, the fluorescence intensity was determined every 15 minutes (starting by the addition of the substrate) for a 1-2 hours final incubation time, using a Synergy HT Multi-mode microplate reader (Biotek). The activities were calculated from the maximal slope of the fluorescence intensity vs time curves and corrected by the amount of protein added. The results were then normalized by the activity observed in 6 months WT mice or 6 months PS1/APP mice (for BACE-1).

Also for each enzymatic activity, a reaction without substrate, a reaction without sample, and reaction with an inhibitor were used as negative controls. The inhibitors used were: Cathepsin B, Inhibitor Ref. 219385 (Callbiochem); Cathepsin D, pepstatin A Solution Ref. P3749 (Sigma-Aldrich); Proteasome $10 \mu \mathrm{M}$ MG-132 (SigmaAldrich). Independently of the enzymatic activity assay, each experiment was repeated, at least, three times for each age and genotype.

Gamma-secretase activity was determined following previously described protocols with some modifications [62]. Briefly, membrane pellets from PS1/APP animals $(\mathrm{n}=6$ per age) were thawed and resuspended (at $3 \mathrm{mg}$ of protein per $\mathrm{ml}$ ) in $150 \mathrm{mM}$ Citrate Buffer, $\mathrm{pH}$ 6.4, containing protease inhibitors (Roche). Aliquots $(150 \mu \mathrm{g}$ of proteins) were used for each assay. As negative control, $100 \mu \mathrm{M}$ L-685-458 gamma-secretase inhibitor (Calbiochem) was added prior assay. Samples were then incubated, at $37^{\circ} \mathrm{C}$ with orbital shaking at $400 \mathrm{rpm}$, for 2 hours. After incubation, membranes were sonicated (at 80 W for 30 seconds) and centrifuged at 30,000xg (30 minutes, $4^{\circ} \mathrm{C}$ ). Supernatants were used to determine AICD production by western blot using anti-APP C-terminal as primary antibody. 


\section{Tissue preparation for immunohistochemistry}

After anesthesia with sodium pentobarbital $(60 \mathrm{mg} / \mathrm{kg})$, 6, 12, and 18-month-old control (WT) and PS1/APP tg male mice $(n=4 /$ age/genotype) were perfused transcardially with $0.1 \mathrm{M}$ phosphate-buffered saline (PBS), $\mathrm{pH}$ 7.4 followed by $4 \%$ paraformaldehyde, $75 \mathrm{mM}$ lysine, 10 $\mathrm{mM}$ sodium metaperiodate in $0.1 \mathrm{M}$ phosphate buffer (PB), pH 7.4. Brains were then removed, post-fixed overnight in the same fixative at $4^{\circ} \mathrm{C}$, cryoprotected in $30 \%$ sucrose, sectioned at $40 \mu \mathrm{m}$ thickness in the coronal plane on a freezing microtome and serially collected in wells containing cold PBS and $0.02 \%$ sodium azide. All animal experiments were approved by the Committee of Animal Use for Research of the Malaga University (Spain) and the European Union Regulations.

\section{Immunohistochemistry}

Coronal free-floating brain sections (40 $\mu$ m thick) from 6 and 12-18 month-old control (WT) and PS1/APP mice were processed simultaneously in the same solutions and conditions to prevent processing variables. Sections were first treated with $3 \% \mathrm{H}_{2} \mathrm{O}_{2} / 3 \%$ methanol in PBS and with avidin-biotin Blocking Kit (Vector Labs, Burlingame, CA, USA), and then incubated overnight at room temperature with one of the following antibodies: anti-APP-C-terminal rabbit polyclonal (1:20,000; Sigma-Aldrich), anti-phosphoSer199:202:Thr205-PHF-tau mouse monoclonal (clone AT8; 1:500; Pierce) anti-ubiquitin rabbit polyclonal (1:2,000, Dako), anti-LC3 goat polyclonal (1:1,000, Santa Cruz Biotechnology), anti-BACE-1 rabbit polyclonal (1:1,000, Abcam) or anti-Lamp2 rabbit polyclonal (1:500, Abcam).

The tissue-bound primary antibody was detected by incubating with the corresponding biotinylated secondary antibody (1:500 dilution, Vector Laboratories), and then followed by streptavidin-conjugated peroxidase (Sigma Aldrich) diluted 1:2000. The reaction was visualized with $0.05 \%$ 3-3'-diaminobenzidine tetrahydrochloride (DAB, Sigma Aldrich), 0.03\% nickel ammonium sulphate and $0.01 \%$ hydrogen peroxide in PBS. When required, immunolabeled sections were then incubated for 3 minutes in a solution of $20 \%$ Congo red. Sections were then mounted on gelatin-coated slides, air dried, dehydrated in graded ethanols, cleared in xylene and coverslipped with DPX (BDH) mounting medium. Specificity of the immune reactions was controlled by omitting the primary antiserum.

\section{Quantitative analysis of Abeta plaques-associated dystrophic neurites}

The number of APP-immunopositive dystrophic neurites per plaque was quantified over Congo red stained Abeta deposits in sections from PS1/APP animals at young (4 and 6 month-old group) and old (12 and 18 monthsold group) ages $(n=6 /$ group; 5 sections per animal through the antero-posterior extent of the hippocampus). Quantification was done in CA1 subfield which was defined using a 10x objective and the number of dystrophic neurites was counted using a 100x objective in an Olympus BX61 microscope equiped with NewCAST software package (Olympus, Glostrup, Denmark). All plaques present in the CA1 region of each section were quantified. The number of dystrophic neurites per plaque was normalized to the mean plaque area to allow comparisons between groups.

\section{Synaptosome and microsome fractions isolation}

Synaptosomal fractions were obtained basically as described previously $[17,63]$ ) with some modifications. Briefly, one mouse hemicortex was gently homogenized with a glass Dounce homogenizer in cold Buffer A $(0.32$ $M$ sucrose, $1 \mathrm{mM}$ EDTA, $1 \mathrm{mM}$ EGTA in $20 \mathrm{mM}$ Tris$\mathrm{HCl} \mathrm{pH} \mathrm{7.5,} \mathrm{plus} 1 \mathrm{mM}$ sodium orthovanadate, $50 \mathrm{mM}$ sodium floride and a complete protease inhibitor cocktail (Roche) at a ratio of $40-50 \mathrm{mg}$ of tissue per $\mathrm{ml}$ of buffer. This homogenate was first centrifuged at $1500 \mathrm{~g}$ and the post-nuclear supernatant was again centrifuged at $12,600 \mathrm{~g}$ for 20 minutes at $4^{\circ} \mathrm{C}$ to get the crude synaptosomes fraction. This pellet was resuspended in $13 \%$ (w:v) (final concentration) Ficoll PM400 (in buffer A) and layered on the bottom of a discontinuous gradient, composed by buffer A and 7\% Ficoll (in buffer A). The gradient was centrifuged at $100,000 \mathrm{~g}\left(45\right.$ minutes, $4^{\circ} \mathrm{C}$ ) in a TLS-55 swimming bucket rotor (Beckman-Coulter), and synaptosomes were isolated at the 7.5-13\% interface. After washing (twice with buffer A), the pellet of synaptosomes was resuspended in Buffer A. The possible contamination with vacuolated postsynapses was evaluated by testing the presence of tau (presynaptic) and MAP2 (postsynaptic) proteins. Results (not shown) indicated the existence of a minimal contamination with vacuolated postsynapses.

On the other hand, the microsomal fraction was obtained after additional centrifugation of the $12,600 \mathrm{~g}$ supernatant at $100,000 \mathrm{~g}$ ( 1 hour, $4^{\circ} \mathrm{C}$ ) in a TLA-110 rotor (Beckman-Coulter). The pellet of microsomes was also resuspended in Buffer A. The protein content of the both synaptosomal and microsomal fractions was determined by Lowry.

\section{APPswe-expressing N2a cultures}

APPswe-stably transfected Neuroblastoma cells were generously donated by Dr. Gopal Thinakaran (University of Chicago) [35]. N2aAPPswe cells were cultured in high glucose DMEM-Optimem (50\%-50\%) supplemented with $2 \mathrm{mM}$ glutamine and $5 \%$ fetal bovine serum (PPA Company), in presence of Penicillin and Streptomycin (100 units/ml and $0.01 \mathrm{mg} / \mathrm{ml}$ respectively) and G418 (PPA Company) as clonal selection antibiotic $(0.2 \mu \mathrm{g} / \mathrm{ml})$ 
[35]. For cell drug treatments, a $0.2 \mu \mathrm{m}$ filtered stock solution of Chloroquine diphosphate salt (Sigma-Aldrich) or MG132 (Sigma-Aldrich) were diluted in the same media at a final concentration of 10 or $5 \mu \mathrm{M}$, respectively. This media was kept for 6 or 24 hours before collecting the cells and isolating RNA and protein as described above.

\section{Statistical analysis}

Data were expressed as mean $\pm \mathrm{SD}$. The comparison between two mice groups (WT and PS1/APP mice) was done by $t$ test. For comparison between several age groups, we used one-way ANOVA followed by Tukey post hoc multiple comparisons test (Statgraphics plus 3.1). As stated above, for most experiments, the different xgroups were compared with 6-month-old WT mice. In some cases (Figures $4 \mathrm{~A}, \mathrm{E}$ and F; Figure $5 \mathrm{C}$ and D) 6-month-old PS1/APP mice were used as reference. The significance was set at $95 \%$ of confidence.

\begin{abstract}
Abbreviations
AD: Alzheimer disease; APP: Amyloid Precursor Protein; A : Amyloid $\beta$ protein; BACE-1: Beta-Secretase-1; CTF: Carboxyl-Terminal-Fragment; LC3: Microtubule-Associated Protein Light Chain 3; PS1: Presenilin-1.
\end{abstract}

\section{Competing interest}

The authors declare that they have no competing interests.

\section{Authors' contributions}

MT, SJ, IC, VN and MV carried out the molecular experiments; R S-V, L T-E, and $\mathrm{E} M-\mathrm{S}$ carried out the immunohistochemical experiments, JCD and MV participated in the design of experiment and revising the manuscript, AG and $\mathrm{JV}$ design the experiments, analyzed the data and wrote the manuscript. All authors read and approved the final manuscript.

\section{Acknowledgements}

This work was supported by grants PS09/00151 (to JV) and PS09/00099 (to AG) from Fondo de Investigación Sanitaria (Instituto de Salud Carlos III, Spain), by grants CTS-4795 (to JV) and SAS PI-0496/2009 (to AG) from Junta de Andalucía (Spain) and by CIBERNED grant PI2010/08 (to JV and AG). MT, $\mathrm{SJ}$ and RS-V were the recipients of a contract from CIBERNED. VN was the recipient of a PhD fellowship granted by the Spanish FPI Program ES-M and LT-E held a PhD fellowship from the Spanish FPU Program. We thank Dr. G Thinakaran for the generous gift of transfected N2a-APPswe cells.

\section{Author details \\ ${ }^{1}$ Instituto de Biomedicina de Sevilla (IBIS), Hospital Universitario Virgen del Rocio, Consejo Superior de Investigaciones Cientificas Universidad de Sevilla, c/ Manuel Siurot s/n, 41013 Sevilla, Spain. ${ }^{2}$ Department Bioquimica y Biologia Molecular, Facultad de Farmacia, Universidad de Sevilla, Sevilla 41012, Spain. ${ }^{3}$ Centro de Investigacion Biomedica en Red sobre Enfermedades Neurodegenerativas (CIBERNED), Madrid, Spain. ${ }^{4}$ Department Biologia Celular, Genetica y Fisiologia, Facultad de Ciencias, Universidad de Malaga, Malaga 29071, Spain.}

Received: 2 August 2012 Accepted: 4 November 2012 Published: 22 November 2012

\section{References}

1. Castellani RJ, Rolston RK, Smith MA: Alzheimer Disease. Dis Mon 2010, 56:484-546.

2. Su JH, Cummings BJ, Cotman CW: Identification and distribution of axonal dystrophic neurites in Alzheimer's disease. Brain Res 1993, 625:228-237.

3. Nixon RA, Wegiel J, Kumar A, Yu WH, Peterhoff C, Cataldo A, et al: Extensive involvement of autophagy in Alzheimer disease: an immuno-electron microscopy study. J Neuropathol Exp Neurol 2005, 64:113-122.
4. Nixon RA: Autophagy, amyloidogenesis and Alzheimer disease. J Cell Sci 2007, 120:4081-4091.

5. Boland B, Kumar A, Lee S, Platt FM, Wegiel J, Yu WH, et al: Autophagy induction and autophagosome clearance in neurons: relationship to autophagic pathology in Alzheimer's disease. J Neurosci 2008, 28:6926-6937.

6. Lee JH, Yu WH, Kumar A, Lee S, Mohan PS, Peterhoff CM, et al: Lysosomal proteolysis and autophagy require presenilin 1 and are disrupted by alzheimer-related ps1 mutations. Cell 2010, 141:1146-1158.

7. Nixon RA, Yang DS: Autophagy failure in Alzheimer's disease--locating the primary defect. Neurobiol Dis 2011, 43:38-45.

8. Nixon RA, Yang DS: Autophagy failure in Alzheimer's disease-locating the primary defect. Neurobiol Dis 2011, 43:38-45.

9. Yang DS, Stavrides P, Mohan PS, Kaushik S, Kumar A, Ohno M, et al: Reversal of autophagy dysfunction in the TgCRND8 mouse model of Alzheimer's disease ameliorates amyloid pathologies and memory deficits. Brain 2011, 134:258-277.

10. Jimenez S, Baglietto-Vargas D, Caballero C, Moreno-Gonzalez I, Torres M, Sanchez-Varo R, et al: Inflammatory response in the hippocampus of PS1M146L/APP751SL mouse model of Alzheimer's Disease: agedependent switch in the microglial phenotype from alternative to classic. J Neurosci 2008, 28:11650-11661.

11. Jimenez S, Torres M, Vizuete M, Sanchez-Varo R, Sanchez-Mejias E, TrujilloEstrada $\mathrm{L}$, et al: Age-dependent accumulation of soluble amyloid beta oligomers reverses the neuroprotective effect of soluble amyloid precursor protein-alpha (sAPPalpha) by Modulating Phosphatidylinositol 3-Kinase (PI3K)/Akt-GSK-3beta pathway in Alzheimer mouse model. J Biol Chem 2011, 286:18414-18425.

12. Lee EB, Leng LZ, Zhang B, Kwong L, Trojanowski JQ, Abel T, et al: Targeting amyloid-beta peptide (Abeta) Oligomers by passive immunization with a conformation-selective monoclonal antibody improves learning and memory in abeta precursor protein (APP) transgenic mice. $J$ Biol Chem 2006, 281:4292-4299.

13. LaFerla FM, Green KN, Oddo S: Intracellular amyloid-[beta] in Alzheimer's disease. Nat Rev Neurosci 2007, 8:76-82.

14. Aguzzi A, Haass C: Games played by rogue proteins in prion disorders and Alzheimer's disease. Science 2003, 302:814-818.

15. Cao X, Sudh of TC: Dissection of amyloid-beta precursor protein-dependent transcriptional transactivation. J Biol Chem 2004, 279:24601-24611.

16. Runz H, Rietdorf J, Tomic I, de Bernard M, Beyreuther K, Pepperkok R, et al: Inhibition of intracellular cholesterol transport alters presenilin localization and amyloid precursor protein processing in neuronal cells. J Neurosci 2002, 22:1679-1689.

17. Sanchez-Varo R, Trujillo-Estrada L, Sanchez-Mejias E, Torres M, BagliettoVargas D, Moreno-Gonzalez I, et al: Abnormal accumulation of autophagic vesicles correlates with axonal and synaptic pathology in young Alzheimer s mice hippocampus. Acta Neuropathol 2012, 123:53-70.

18. Yu WH, Kumar A, Peterhoff C, Shapiro Kulnane L, Uchiyama Y, Lamb BT, et al: Autophagic vacuoles are enriched in amyloid precursor proteinsecretase activities: implications for [beta]-amyloid peptide overproduction and localization in Alzheimer's disease. Int J Biochem Cell Biol 2004, 36:2531-2540.

19. Yu WH, Cuervo AM, Kumar A, Peterhoff CM, Schmidt SD, Lee JH, et al: Macroautophagy-a novel \{beta\}-amyloid peptide-generating pathway activated in Alzheimer's disease. J Cell Biol 2005, 171:87-98.

20. Pasternak SH, Bagshaw RD, Guiral M, Zhang S, Ackerley CA, Pak BJ, et al: Presenilin-1, Nicastrin, Amyloid Precursor Protein, and \{gamma\}secretase activity Are Co-localized in the lysosomal membrane. J Biol Chem 2003, 278:26687.

21. Miners JS, Barua N, Kehoe PG, Gill S, Love S: Abeta-degrading enzymes: potential for treatment of Alzheimer disease. J Neuropathol Exp Neurol 2011, 70:944-959.

22. Almeida CG, Takahashi RH, Gouras GK: Beta-amyloid accumulation impairs multivesicular body sorting by inhibiting the ubiquitin-proteasome system. J Neurosci 2006, 26:4277-4288.

23. Han BH, Zhou M, Abousaleh F, Brendza RP, Dietrich HH, KoenigsknechtTalboo J, et al: Cerebrovascular dysfunction in amyloid precursor protein transgenic mice: contribution of soluble and insoluble amyloid-\{beta\} peptide, partial restoration via \{gamma\}-secretase inhibition. $J$ Neurosci 2008, 28:13542-13550.

24. Oddo S, Caccamo A, Tseng B, Cheng D, Vasilevko V, Cribbs DH, et al: Blocking A\{beta\} 42 accumulation delays the onset and progression of tau pathology via the $\mathrm{C}$ terminus of heat shock protein70-interacting 
protein: a mechanistic link between $\mathrm{A}\{$ beta\} and Tau Pathology J Neurosci 2008, 28:12163-12175.

25. Wang X, Perry G, Smith MA, Zhu X: Amyloid beta derived diffusible ligands cause impaired axonal transport of mitochondria in neurons. Neurodeg Dis 2010, 7:56-59.

26. Butler D, Hwang J, Estick C, Nishiyama A, Kumar SS, Baveghems C, et al: Protective effects of positive lysosomal modulation in Alzheimer's disease transgenic mouse models. PLoS One 2011, 6:e20501.

27. Ramos B, Baglietto-Vargas D, Rio JC, Moreno-Gonzalez I, Santa-Maria C, Jimenez S, et al: Early neuropathology of somatostatin/NPY GABAergic cells in the hippocampus of a PS1 x APP transgenic model of Alzheimer's disease. Neurobiol Aging 2006, 27:1658-1672.

28. Veeranna, Kaji T, Boland B, Odrljin T, Mohan P, Basavarajappa BS, et al: Calpain mediates calcium-induced activation of the Erk1,2 MAPK Pathway and Cytoskeletal Phosphorylation in Neurons: relevance to Alzheimer's disease. Am J Pathol 2004, 165:795-805.

29. Shahpasand K, Uemura I, Saito T, Asano T, Hata K, Shibata K, et al: Regulation of mitochondrial transport and inter-microtubule spacing by Tau Phosphorylation at the sites hyperphosphorylated in Alzheimer's disease. J Neurosci 2012, 32:2430-2441.

30. Bednarski E, Ribak CE, Lynch G: Suppression of Cathepsins B and L causes a proliferation of lysosomes and the formation of meganeurites in hippocampus. J Neurosci 1997, 17:4006-4021.

31. Bi X, Zhou J, Lynch G: Lysosomal protease inhibitors induce meganeurites and tangle-like structures in entorhinohippocampal regions vulnerable to Alzheimer's disease. Exp Neurol 1999, 158:312-327.

32. Lee $S$, Sato $Y$, Nixon RA: Lysosomal proteolysis inhibition selectively disrupts axonal transport of Degradative organelles and causes an Alzheimer's-like axonal dystrophy. J Neurosci 2011, 31:7817-7830.

33. Cai Q, Lu L, Tian JH, Zhu YB, Qiao H, Sheng ZH: Snapin-regulated late endosomal transport is critical for efficient autophagy-Lysosomal function in neurons. Neuron 2010, 68:73-86.

34. Caballero C, Jimenez S, Moreno-Gonzalez I, Baglietto-Vargas D, Sanchez-Varo $R$, Gavilan M, et al: Inter-individual variability in the expression of the mutated form of hPS1M146L determined the production of Abeta peptides in the PS1xAPP transgenic mice. J Neurosci Res 2007, 85:787-797.

35. Vetrivel KS, Cheng H, Kim SH, Chen Y, Barnes NY, Parent AT, et al: Spatial segregation of gamma -secretase and substrates in distinct membrane domains. J Biol Chem 2005, 280:25892-25900.

36. Fifre A, Sponne I, Koziel V, Kriem B, Potin FTY, Bihain BE, et al: Microtubuleassociated Protein MAP1A, MAP1B, and MAP2 Proteolysis during Soluble Amyloid \{beta\}-Peptide-induced Neuronal Apoptosis: SYNERGISTIC INVOLVEMENT OF CALPAIN AND CASPASE-3. J Biol Chem 2006, 281:229-240.

37. Higuchi M, Iwata N, Matsuba Y, Takano J, Suemoto T, Maeda J, et al: Mechanistic involvement of the calpain-calpastatin system in Alzheimer neuropathology. FASEB J 2012, 26:1204-1217.

38. Liang B, Duan BY, Zhou XP, Gong JX, Luo ZG: Calpain activation promotes BACE1 expression, amyloid precursor protein processing, and amyloid plaque formation in a transgenic mouse model of Alzheimer disease. $J$ Biol Chem 2010, 285:27737-27744.

39. Amadoro G, Corsetti V, Ciotti MT, Florenzano F, Capsoni S, Amato G, et al: Endogenous Abeta causes cell death via early tau hyperphosphorylation. Neurobiol Aging 2011, 32:969-990.

40. Kilinc D, Gallo G, Barbee KA: Mechanical membrane injury induces axonal beading through localized activation of calpain. Exp Neurol 2009, 219:553-561.

41. Noda-Saita K, Terai K, Iwai A, Tsukamoto M, Shitaka Y, Kawabata S, et al: Exclusive association and simultaneous appearance of congophilic plaques and AT8-positive dystrophic neurites in Tg2576 mice suggest a mechanism of senile plaque formation and progression of neuritic dystrophy in Alzheimer disease. Acta Neuropathol 2004, 108:435-442.

42. Tang Y, Scott DA, Das U, Edland SD, Radomski K, Koo EH, et al: Early and Selective Impairments in Axonal Transport Kinetics of Synaptic Cargoes Induced by Soluble Amyloid beta Protein Oligomers. Traffic 2012, 13:681-693.

43. Zempel H, Thies E, Mandelkow E, Mandelkow EM: Abeta oligomers cause localized $\mathrm{Ca} 2+$ elevation, missorting of endogenous tau into dendrites, Tau Phosphorylation, and destruction of microtubules and spines. J Neurosci 2010, 30:11938-11950.

44. Zhang X, Garbett K, Veeraraghavalu K, Wilburn B, Gilmore R, Mirnics K, et al: A role for presenilins in autophagy revisited: normal acidification of lysosomes in cells lacking PSEN1 and PSEN2. J Neurosci 2012, 32:8633-8648.
45. Mueller-Steiner S, Zhou Y, Arai H, Roberson ED, Sun B, Chen J, et al: Antiamyloidogenic and neuroprotective functions of cathepsin $B$ implications for Alzheimer's disease. Neuron 2006, 51:703-714.

46. Asai M, Yagishita S, Iwata N, Saido TC, Ishiura S, Maruyama K: An alternative metabolic pathway of amyloid precursor protein C-terminal fragments via cathepsin B in a human neuroglioma model. FASEB J 2011, 25:3720-3730.

47. Koh YH, von Arnim CAF, Hyman BT, Tanzi RE, Tesco G: BACE is degraded via the lysosomal pathway. J Biol Chem 2005, 280:32499-32504.

48. Jin M, Shepardson N, Yang T, Chen G, Walsh D, Selkoe DJ: Soluble amyloid beta protein dimers isolated from Alzheimer cortex directly induce Tau hyperphosphorylation and neuritic degeneration. Proc Natl Acad Sci USA 2011, 108:5819-5824.

49. Lee S, Sato Y, Nixon RA: Primary lysosomal dysfunction causes cargospecific deficits of axonal transport leading to Alzheimer-like neuritic dystrophy. Autophagy 2011, 7:1562-1563.

50. Vassar R, Kovacs DM, Yan R, Wong PC: The beta-secretase enzyme BACE in health and Alzheimer's disease: regulation, cell biology, function, and therapeutic potential. J Neurosci 2009, 29:12787-12794.

51. Saura CA, Serviaín-Morilla E, Scholl FG: Presenilin/gamma secretase regulates neurexin processing at synapses. PLoS One 2011, 6:e19430

52. Boland B, Smith DA, Mooney D, Jung SS, Walsh DM, Platt FM: Macroautophagy is not directly involved in the metabolism of amyloid precursor protein. J Biol Chem 2010, 285:37415-37426

53. Cirrito JR, Kang JE, Lee J, Stewart FR, Verges DK, Silverio LM, et al: Endocytosis is required for synaptic activity-dependent release of amyloid-beta in vivo. Neuron 2008, 58:42-51.

54. Harris JA, Devidze N, Verret L, Ho K, Halabisky B, Thwin MT, et al: Transsynaptic progression of amyloid beta induced neuronal dysfunction within the entorhinal-hippocampal network. Neuron 2010, 68:428-441.

55. Ronnback A, Sagelius H, Bergstedt KD, Naslund J, Westermark GT, Winblad $B$, et al: Amyloid neuropathology in the single Arctic APP transgenic model affects interconnected brain regions. Neurobiol Aging 2012, 33:831.

56. DeCalignon A, Polydoro M, Suarez-Calvet M, William C, Adamowicz D, Kopeikina K, et al: Propagation of tau pathology in a model of early Alzheimer's disease. Neuron 2012, 73:685-697.

57. Liu L, Drouet V, Wu JW, Witter MP, Small SA, Clelland C, et al: Transsynaptic spread of tau pathology in vivo. PLoS One 2012, 7:e31302

58. Moreno-Gonzalez I, Baglietto-Vargas D, Sanchez-Varo R, Jimenez S, Trujilloestrada L, Sanchez-mejias $E$, et al: Extracellular amyloid- $B$ and cytotoxic glial activation induce significant entorhinal neuron loss in young PS1 M146L APP 751SL mice. J Alzheimers Dis 2009, 18:755-776.

59. Blanchard V, Moussaoui S, Czech C, Touchet N, Bonici B, Planche M, et al: Time sequence of maturation of dystrophic neurites associated with $A$ [beta] deposits in APP/PS1 transgenic mice. Exp Neurol 2003, 184:247-263.

60. Araujo F, Tan S, Ruano D, Schoemaker H, Benavides J, Vitorica J: Molecular and pharmacological characterization of native cortical gammaaminobutyric acid(A) receptors containing both alpha(1) and alpha(3) subunits. J Biol Chem 1996, 271:27902-27911.

61. Gavilan MP, Pintado C, Gavilan E, Jimenez S, Rios RM, Vitorica J, et al: Dysfunction of the unfolded protein response increases neurodegeneration in aged rat hippocampus following proteasome inhibition. Aging Cell 2009, 8:654-665.

62. Tamboli IY, Hampel H, Tien NT, Tolksdorf K, Breiden B, Mathews PM, et al: Sphingolipid storage affects autophagic metabolism of the amyloid precursor protein and promotes abeta generation. J Neurosci 2011, 31:1837-1849.

63. Vitorica J, Satrustegui J: Involvement of mitochondria in the age-dependent decrease in calcium uptake of rat brain synaptosomes. Brain Res 1986, 378:36-48.

doi:10.1186/1750-1326-7-59

Cite this article as: Torres et al:: Defective lysosomal proteolysis and axonal transport are early pathogenic events that worsen with age leading to increased APP metabolism and synaptic Abeta in transgenic APP/PS1 hippocampus. Molecular Neurodegeneration 2012 7:59. 